\title{
Analysis of Some Mechanical Properties of Hybrid Matrix Composites Reinforced by Flax Fabric. Orthopaedic Applications
}

\author{
VLAD ALEXANDRU GEORGEANU1, DUMITRU BOLCU ${ }^{2}$, \\ MARIUS MARINEL STANESCU ${ }^{2 *}$ ION CIUCA ${ }^{3}$, VICTORITA STEFANESCU ${ }^{4 *}$, \\ ROBERT CIOCOIU ${ }^{3}$, MARIA ALEXANDRA IVAN ${ }^{3}$ \\ ${ }^{1}$ University of Medicine and Pharmacy "Carol Davila" Bucharest, Faculty of Medicine, 37 Dionisie Lupu, 020021, Bucharest, \\ Romania \\ ${ }^{2}$ University of Craiova, Faculty of Mechanics, 165 Calea Bucuresti, 200620, Craiova, Romania \\ ${ }^{3}$ Politehnica University of Bucharest, Faculty of Engineering and Materials Science, 313 Splaiul Independentei, 060042, \\ Bucharest, Romania \\ ${ }^{4}$ Dunarea de Jos University of Galati, Faculty of Medicine and Pharmacy, 47 Domneasca Str., 800008, Galati, Romania
}

\begin{abstract}
Great interest has been shown lately in bio-composite materials because they are inexpensive and sustainable. Composites with matrices and natural reinforcers have been little studied. Here, we study certain mechanical properties of composite materials with a Dammar-based matrix (also named hybrid matrix) and flax fabric reinforcement. To be precise, we examine three types of resins where Dammar is the major component, with a volume proportion of 55\%, 65\% and 75\%. In this respect, we have made composite materials reinforced by two types of flax fabric and we have measured the characteristic curves and some mechanical properties, such as the Young's modulus, tensile strength and elongation at break using tensile tests. Based on the obtained properties, it is proposed or possible to use these materials in orthopedics.
\end{abstract}

Keywords: composite materials, hybrid matrix, natural fibers, mechanical properties

\section{Introduction}

Bio-composites that have both matrix and reinforcer made of natural materials are increasingly used because they are environmentally friendly compared to conventional petroleum-based materials.

The use as a reinforcer of natural fibers instead of synthetic ones in the structure of polymers, has certain disadvantages, such as: excessive water absorption, low thermal properties, etc. Finding effective solutions to improve or eliminate these disadvantages is a challenge for researchers in this field. In the case of matrices, there are situations where the use of thermosetting-biological resins based on vegetable oil resins instead of synthetic resins is indicated. One such example is injection molding where vegetable resins do not need a polymerization process, and synthetic resins can only withstand certain processes because they have a high melt viscosity. A possibility for the disposal of plastics waste obtained from oil is biodegradable polymers. In order for biodegradable polymers to have a low price with which to compete economically on the market, it is necessary to find applications that consume sufficiently large quantities of these materials [1-3].

Biopolymers are obtained from sustainable resources and, accordingly, they have been given increasing attention in comparison with petrol-based polymers [4]. Among the vegetable resins, which are produced by different trees, the most used are Sandarac, Copal and Dammar. An advantage of these resins is that they are insoluble in water. They can form (by dilution with gasoline, oil or alcohol) solutions used as coating varnishes [5-9]. As they cannot form thick resins (the works can be consulted for justification $[5,6]$ ) these coating varnishes have been and are used to ensure the shine and protection of furniture, paintings and musical instruments made of wood, by applying them in thin layers. The structure of a hybrid material based on a natural lake and organic epoxy and saline compounds was analyzed by using liquid and solid nuclear magnetic resonance.

*email:mamas1967@gmail.com,victorita_stefanescu@yahoo.com 
The drying, hardness and casting properties of the obtained hybrid resin were analyzed. This drawback can be removed if hybrid resins are used (which contain both organic and synthetic constituents). We must mention that most trials aimed at obtaining such resins have taken place in the lacquer industry [5-7]. Hybrid resins are an eco-friendly alternative to synthetic resins.

One of the most used natural resins is Dammar. This resin is produced by trees of the Dipterocarpaceae family in Southeast Asia. The mechanical properties of natural resins have been little studied. The tensile strength, Young's modulus and other properties related to the mechanical behavior for the Dammar film treated with softening agents were studied in [10]. The way in which the addition of Dammar contributes to improving the rigidity, the Young's modulus and the hardness of modified silicon is studied in [11,12]. The studies regarding this resin have focused mainly on its chemical composition and properties, as shown in detail in [13,14].

The chemical composition of Dammar (tetracyclic Dammarane skeletons, pentacyclic hopane, ursane and oleanane derivatives) made this resin to be used to make drugs. Studies on the influence of crosslinked Dammar gum with biodegradable components based on zirconium and polyacrylamide on the administration of atenolol are made in [15]. Using SEM (Scanning Electron Microscopy) with EDS (Energy Dispersive Spectroscopy) and FTIR (Fourier Transform Infrared Spectroscopy), in [16-18] are analyzed properties of the hydrogel (Dammar gum mixed with zirconium iodate).

Apart from hybrid resins, using natural reinforcements instead of synthetic fibers has been preferred more and more for making biodegradable composite materials [19,20] because, in comparison with synthetic fibers, natural fibers have a biodegradable and sustainable character. Kenaf, hemp, flax, dogbane, henequen, palm leaves, sisal, wood, herbs, corn stalk, cocoanut, and others range among the most used natural fibers. According to studies conducted in [1,21], some mechanical properties of natural fibers, report to the specific gravity, are comparable to those of fiberglass. The mechanical properties of a wide range of natural and synthetic fibers can be found in the works [19-23].

The use as a matrix of hybrid resins together with natural fiber reinforcers generates composite materials "more environmentally friendly" than those made entirely of synthetic materials, or those in which only the reinforcements are natural. There are also few studies about the composite materials that have both their matrix and their reinforcement made of natural materials. The mechanical properties of certain composite materials obtained from Dammar-based hybrid resin, reinforced by flax, cotton, hemp, wheat straw and cattail are analysed in [24]. In the paper [25] is studied the influence of material nonuniformities on the mechanical behavior of composite materials that have the hybrid matrix based on Dammar and the reinforcement of hemp fabric.

Next, some mechanical properties of Dammar-based composite materials will be studied, and the reinforcer will consist of two types of flax fabric. More precisely, the matrix used will consist of a volume proportion of $55 \%, 65 \%$ and $75 \%$ natural Dammar resin, respectively.

The characteristics and mechanical properties of the mentioned material make it particularly attractive in the orthopedics. The different types of pathology (consolidation delays, pseudarthrosis, congenital pseudarthrosis) in which it is necessary a longer period of immobilisatione of the different anatomical segments, as well as the progressive modification of the orthosis according to the local evolution, represent situations in which this material can be applied with good results. Thus, from the composite material with the flax fabric reinforcement and the hybrid matrix with $65 \%$ volumic proportion of Dammar resin, will be made a fixed orthosis to protect the tibia bone against external stresses.

Functional bracing is an effective method in the treatment of selected, low - energy fractures. In the case of tibial fractures, it is applicable for reduced transverse fractures and to axially unstable fractures with minimal shortening. The rate of union of tibial fractures after this method of treatment is around $97 \%$ [26]. 


\section{Materials and methods}

For use in the field of paints Dammar natural resin Dammar is diluted with turpentine (vernis protection). Its disadvantage is that the resin hardening process is very long, even if we apply thin layers. The works [5-7] show that natural lacquers can form thick resins only when synthetic components are included. We solved this shortcoming by adding Resoltech 1050 epoxy resin, together with its Resoltech $1058 \mathrm{~S}$ associated hardener. Henceforth, we will call the new type of resin, obtained by mixing Dammar, turpentine, and epoxy resin with the associated hardener, hybrid resin. The epoxy resin properties (Resoltech 1050/Resoltech $1058 \mathrm{~S}$ ) can be found on the producer's webpage [27].

Three hybrid resin plates were cast in the first stage. The volumic rations of Dammar were $55 \%$ for the first plate, $65 \%$ for the second plate, and $75 \%$ for the third. Thus, $100 \mathrm{~mL}$ of hybrid resin with a volume proportion of 55\% Dammar contain: $50 \mathrm{~mL}$ of natural Dammar resin diluted with turpentine; 5 $\mathrm{mL}$ of Dammar resin powder; $34 \mathrm{~mL}$ Resoltech 1050 epoxy resin; $11 \mathrm{~mL}$ hardener Resoltech $1058 \mathrm{~S}$.

$100 \mathrm{~mL}$ of hybrid resin with a volume proportion of $65 \%$ Dammar contain: $60 \mathrm{~mL}$ of natural Dammar resin diluted with turpentine; $5 \mathrm{~mL}$ of Dammar resin powder; $27 \mathrm{~mL}$ Resoltech 1050 epoxy resin; $11 \mathrm{~mL}$ hardener Resoltech $1058 \mathrm{~S}$.

$100 \mathrm{~mL}$ of hybrid resin with a volume proportion of $75 \%$ Dammar contain: $70 \mathrm{~mL}$ of natural Dammar resin diluted with turpentine; $5 \mathrm{~mL}$ of Dammar resin powder; $19 \mathrm{~mL}$ Resoltech 1050 epoxy resin; $6 \mathrm{~mL}$ hardener Resoltech $1058 \mathrm{~S}$.

The cast plates were kept for 10 days at a constant temperature between $21-23{ }^{0} \mathrm{C}$. Sets of 10 specimens were cut from each plate, which we labelled Dammar 1.1 - 10 for the 55\% Dammar samples, Dammar 2.1 - 10 for the 65\% Dammar samples, Dammar 3.1 - 10 for the 75\% Dammar samples. The size of the samples was $250 \mathrm{~mm}$ long and $25 \mathrm{~mm}$ wide, according to ASTM D3039 [28]. The sample density ranged between $1.04-1.06 \mathrm{~g} / \mathrm{cm}^{3}$.

Figure 1 shows one sample of each set.

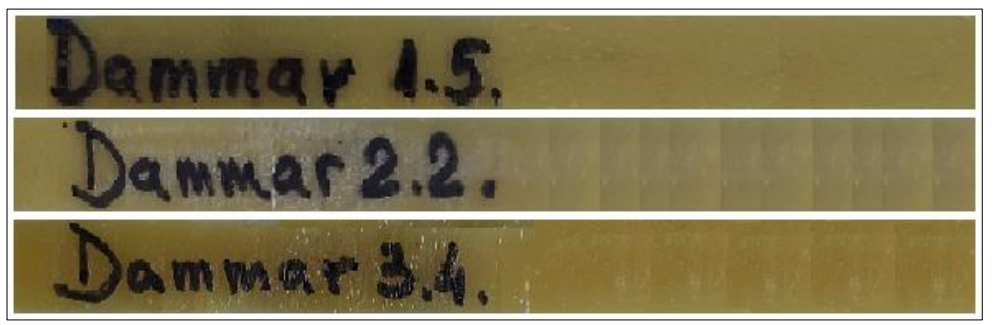

Figure 1. Sample specimens of each set of hybrid resin

In the second stage, composite materials are made from Dammar-based resins by reinforcing with five layers of two types of flax fabric. Reinforced composites with the first type of fabric and the resin matrix with 55\%, 65\% and 75\% Dammar, respectively, with DH1-55, DH1-65 and DH1-75 respectively are strengthened. Composites reinforced with the second type of fabric are symbolized by DH2-55, DH265 and DH2-75 respectively. The flax fiber properties $[1,29,30]$ are: $1.5 \mathrm{~g} / \mathrm{cm}^{3}$ density, 27-39 $G P a$ Young's modulus, 345-1100 $M P a$ tensile strength, 2.7\% -3.2\% elongation at break.

In the case of the first type of fabric, we put 8 layers of the mixture, having $100 \%$ flax; the specific mass of the fabric was $220 \mathrm{~g} / \mathrm{m}^{2}$. The obtained composites had $1.15-1.16 \mathrm{~g} / \mathrm{cm}^{3}$ density, and the resin mass proportions in the plates are shown in Table 2.

In the case of the second type, we put 16 layers of the mixture, having $40 \%$ cotton and $60 \%$ flax, whereas the specific mass of the fabric was $160 \mathrm{~g} / \mathrm{m}^{2}$. The obtained composites had $1.19-1.20 \mathrm{~g} / \mathrm{cm}^{3}$ density, and the resin mass proportions in the plates are shown in Table 3. One may notice that there are no important differences as far as density is concerned in the composites reinforced by the same type of fabric when we change the Dammar proportion in the hybrid resin employed. In addition, it can be seen that the density of composer DH1 is slightly lower than the density of composer DH2. This can be explained both by the density difference between fabrics and by the volume difference. 
Sets of 10 specimens are cut from each plate of composite material. The samples were $250 \mathrm{~mm}$ long, $25 \mathrm{~mm}$ wide. The thickness was $4.0 \mathrm{~mm}$ for the samples of DH1 composite and $5.0 \mathrm{~mm}$ for those of DH2 composite.

All sets of specimens were tested for traction. The provisions of ASTM D3039 have been observed. The traction test was performed with LLOYD Instruments Lrx PLU. The characteristics of this test machine are: maximum tensile force $2.5 \mathrm{kN}$; maximum stroke $735 \mathrm{~mm}$; variable traction speed between $0.1 \mathrm{~mm} / \mathrm{min}$ and $500 \mathrm{~mm} / \mathrm{min}$. NEXYGEN analysis software was used.

From obtained stress-strain diagram were determined: percentage elongation after fracture $\varepsilon$ [\%]; tensile strength $R_{m}[M P a]$; Young's modulus $E[M P a]$.

It should be mentioned that in order to perform the tensile test in optimal conditions, the required samples must have a minimum thickness of $4 \mathrm{~mm}$. Because the densities of the two types of flax fabric used as reinforcement are different, in order to obtain this thickness of the samples, a number of 8 layers of the first type of fabric and 16 layers respectively of the second type of fabric were used.

Figure 2 shows the equipment for the tensile test of a Dammar-based resin sample.

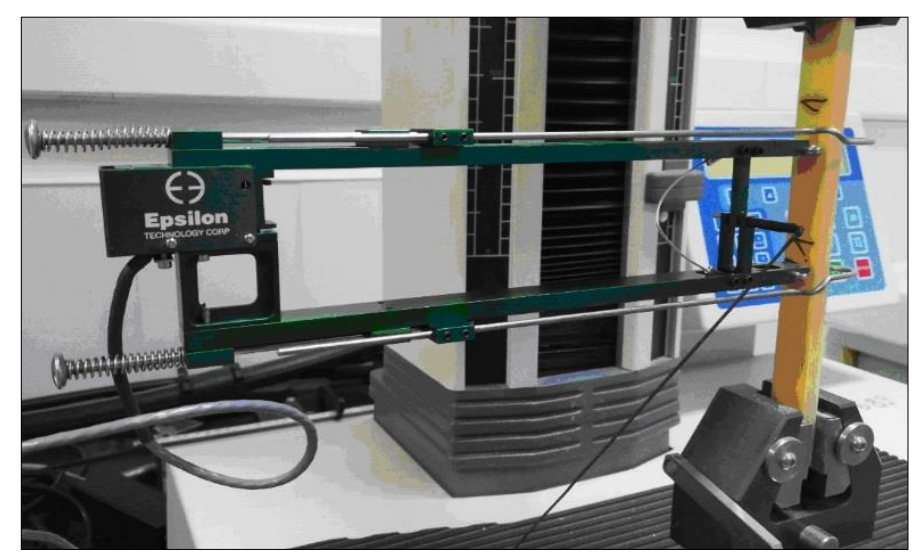

Figure 2. The equipment for the tensile test of a

Dammar-based resin sample

Based on the composite material DH1-65 was casted an orthosis to protect the tibia bone. 4 layers of flax fabric were used, resulting in a thickness of only $2 \mathrm{~mm}$ and a $160 \mathrm{~g}$ weight. Only 4 layers of the higher density fabric were used because this number of layers ensured the simultaneous fulfillment of three conditions:

- low weight;

- the thickness obtained was sufficient to ensure the necessary rigidity;

- allowed the modeling of the orthosis according to the shape of the foot.

The orthosis was fixed with 4 velcro straps for good stability and avoidance of movements that can create injuries of the skin (the final weight of the orthosis with velcro straps was $210 \mathrm{~g}$ ).

\section{Results and discussions}

Figures 3-5 show the stress-strain diagrams of a sample of each set of Dammar-based resin samples. 


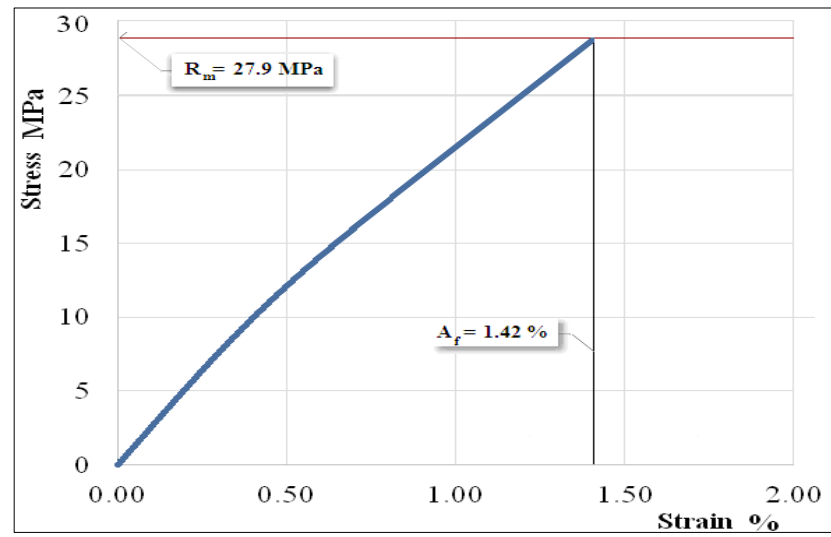

Figure 3. Stress-strain diagram of a Dammar 1.X sample

Percentage elongation at break $\varepsilon=1.42 \%$; tensile strength $R_{m}=27.9 \mathrm{MPa}$; Young's modulus $E=3053 M P a$.

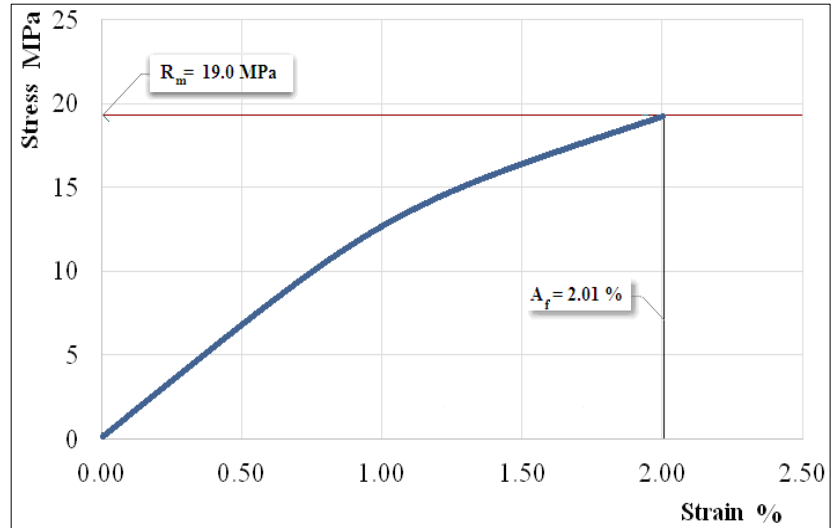

Figure 4. Stress-strain diagram of a Dammar 2.X sample

Percentage elongation at break $\varepsilon=2.01 \%$; tensile strength $R_{m}=19.0 \mathrm{MPa}$; Young's modulus $E=2401 M P a$.

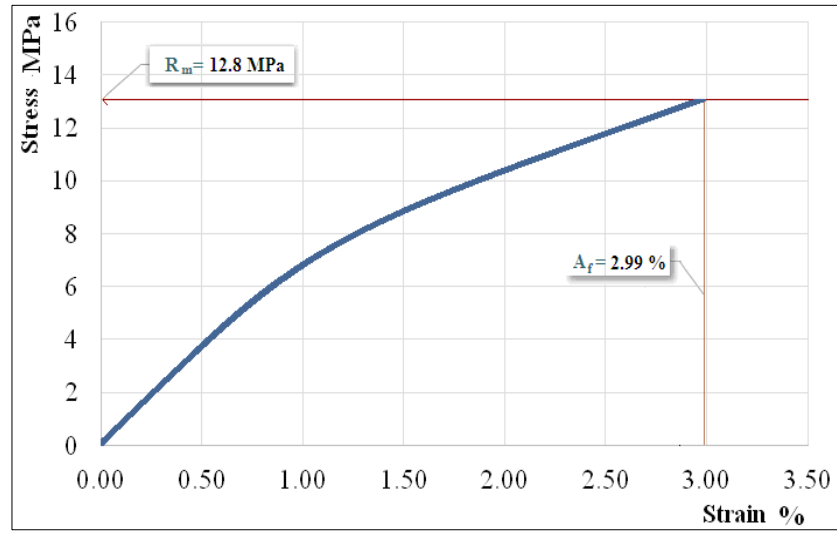

Figure 5. Stress-strain diagram of a Dammar 3.X sample

Percentage elongation at break $\varepsilon=2.99 \%$; tensile strength $R_{m}=12.8 \mathrm{MPa}$; Young's modulus $E=1767 M P a$.

The experimental results for the sets of hybrid resin samples are shown in Table 1. 
Table 1. Extreme values of the studied mechanical properties for the samples of Dammar-based hybrid resin

\begin{tabular}{|c|c|c|c|}
\hline Hybrid resin type & $\begin{array}{c}\text { Elongation at break } \\
\varepsilon[\%]\end{array}$ & $\begin{array}{c}\text { Tensile strength } \\
\mathrm{R}_{\mathrm{m}}[\mathrm{MPa}]\end{array}$ & $\begin{array}{c}\text { Young's modulus } \\
\text { E[MPa] }\end{array}$ \\
\hline Dammar 1.X & $1.38-1.47$ & $26.8-28.8$ & $2980-3070$ \\
\hline Dammar 2.X & $1.93-2.07$ & $18.3-19.4$ & $2330-2450$ \\
\hline Dammar 3.X & $2.93-3.06$ & $12.1-13.6$ & $1700-1790$ \\
\hline
\end{tabular}

The samples made of composite materials reinforced by flax fabric underwent a tensile test, in their turn. Figures 6-8 show the stress-strain diagrams of the DH1 composites.

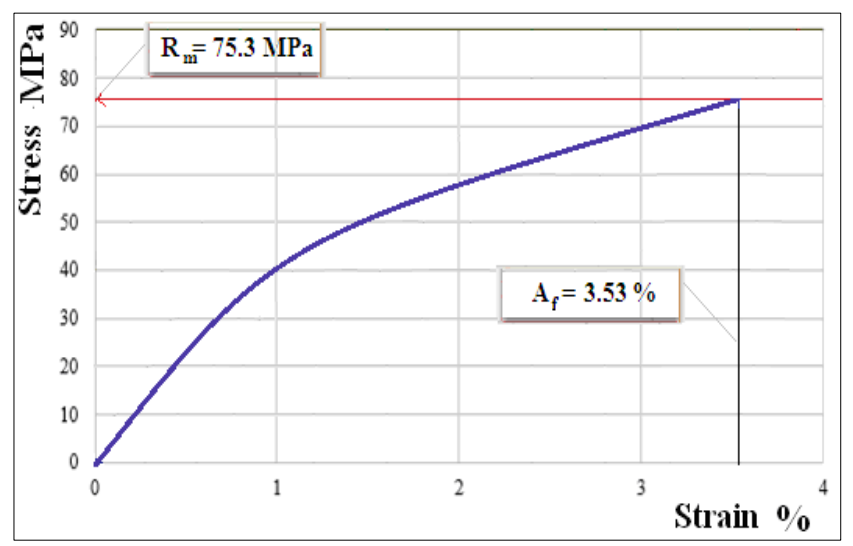

Figure 6. Stress-strain diagram of DH1-55 composite

Percentage elongation after break $\varepsilon=3.53 \%$; tensile strength $R_{m}=75.3 \mathrm{MPa}$; Young's modulus $E=5163 M P a$.

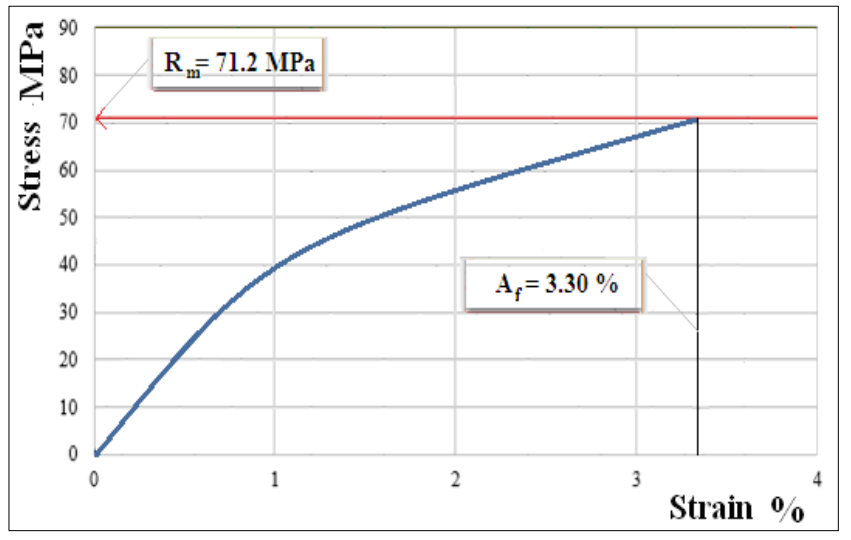

Figure 7. Stress-strain diagram of DH1-65 composite

Percentage elongation after break $\varepsilon=3.30 \%$; tensile strength $R_{m}=71.2 \mathrm{MPa}$; Young's modulus $E=5027 \mathrm{MP} a$. 


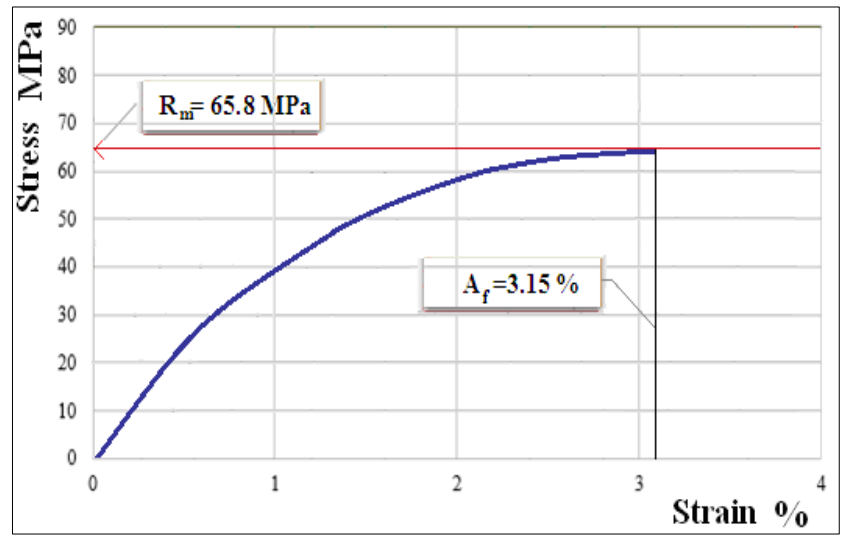

Figure 8. Stress-strain diagram of DH1-75 composite

Percentage elongation after break $\varepsilon=3.15 \%$; tensile strength $R_{m}=65.8 \mathrm{MPa}$; Young's modulus $E=4882 \mathrm{MPa}$.

The experimental results for the sample sets of DH1 composites, are shown in Table 2.

Table 2. Extreme values of the studied mechanical properties for DH1 composites

\begin{tabular}{|c|c|c|c|c|}
\hline $\begin{array}{c}\text { Hybrid resin } \\
\text { mass proportion }\end{array}$ & $\begin{array}{c}\text { Composite } \\
\text { type }\end{array}$ & $\begin{array}{c}\text { Elongation at break } \\
\varepsilon[\%]\end{array}$ & $\begin{array}{c}\text { Tensile strength } \\
\mathrm{R}_{\mathrm{m}}[\mathrm{MPa}]\end{array}$ & $\begin{array}{c}\text { Young's modulus } \\
\text { E[MPa] }\end{array}$ \\
\hline 0.51 & DH1-55 & $3.40-3.61$ & $72.9-76.7$ & $5120-5220$ \\
\hline 0.53 & DH1-65 & $3.20-3.35$ & $70.3-73.2$ & $4980-5050$ \\
\hline 0.51 & DH1-75 & $3.09-3.21$ & $64.4-66.2$ & $4830-4910$ \\
\hline
\end{tabular}

Figures 9-11 show the stress-strain diagrams of the $\mathrm{DH} 2$ composites.

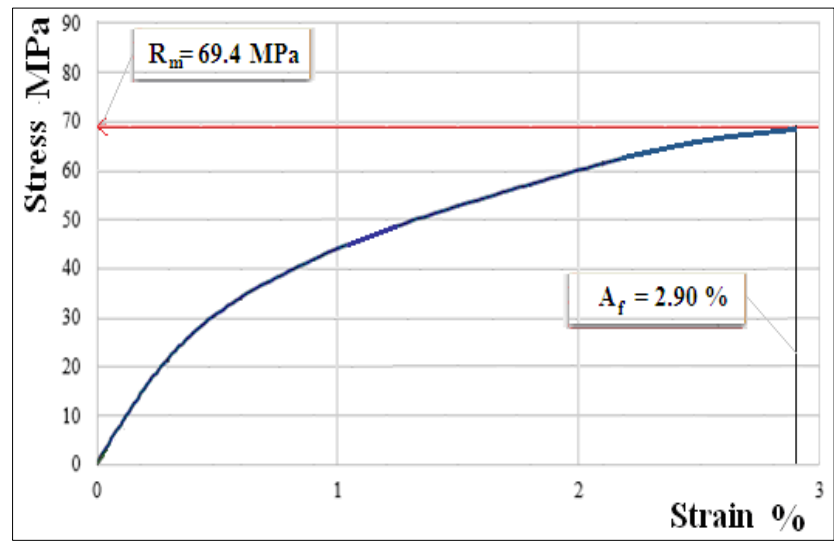

Figure 9. Stress-strain diagram of a DH2-55 composite

Percentage elongation after break $\varepsilon=2.90 \%$; tensile strength $R_{m}=69.4 \mathrm{MPa}$; Young's modulus $E=4852 M P a$. 


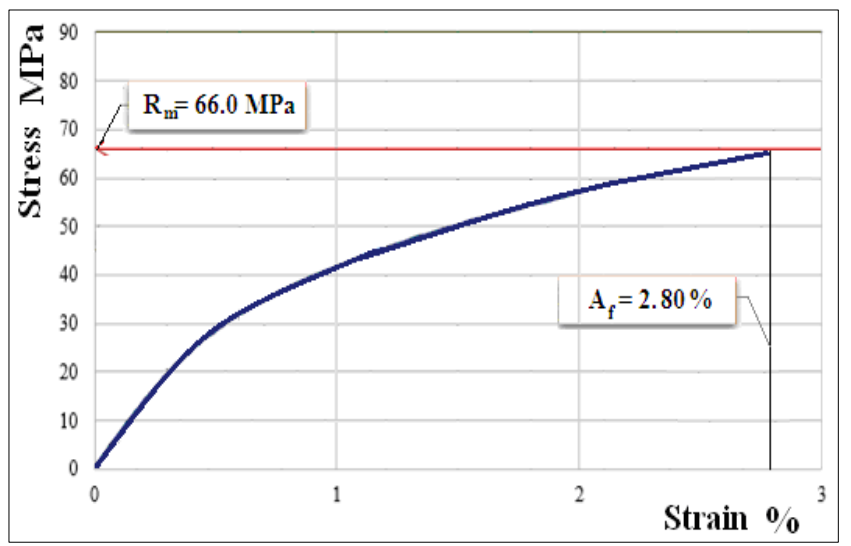

Figure 10. Stress-strain diagram of a DH2-65 composite

Percentage elongation after break $\varepsilon=2.80 \%$; tensile strength $R_{m}=66.0 \mathrm{MPa}$; Young's modulus $E=4680 \mathrm{MPa}$.

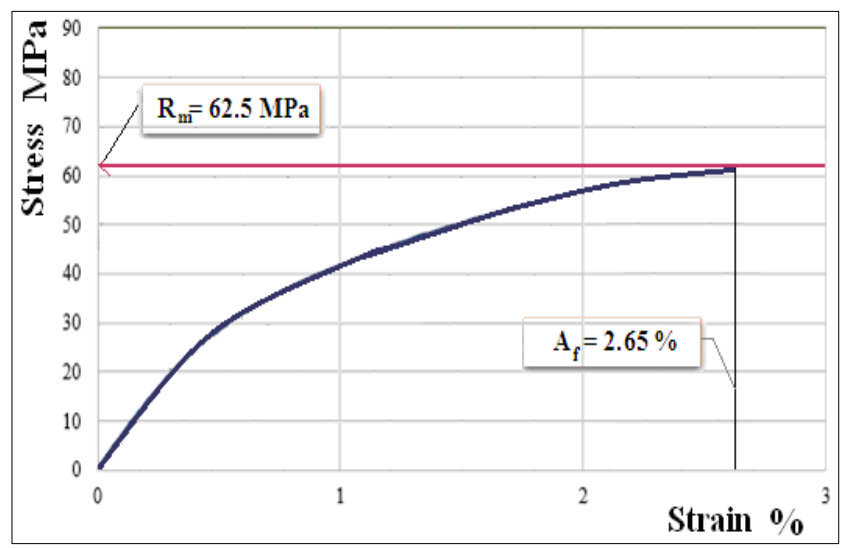

Figure 11. Stress-strain diagram of a DH2-75 composite

Percentage elongation after break $\varepsilon=2.65 \%$; tensile strength $R_{m}=62.5 \mathrm{MPa}$; Young's modulus $E=4613 \mathrm{MPa}$.

The experimental results for the sets of DH2 composites are shown in Table 3.

Table 3. Extreme values of the studied mechanical properties for DH2 composites.

\begin{tabular}{|c|c|c|c|c|}
\hline $\begin{array}{c}\text { Hybrid resin } \\
\text { mass } \\
\text { proportion }\end{array}$ & $\begin{array}{c}\text { Composite } \\
\text { type }\end{array}$ & $\begin{array}{c}\text { Elongation at } \\
\text { break } \\
\varepsilon[\%]\end{array}$ & $\begin{array}{c}\text { Tensile } \\
\text { strength } \\
\mathrm{R}_{\mathrm{m}}[\mathrm{MPa}]\end{array}$ & $\begin{array}{c}\text { Young's } \\
\text { modulus } \\
\text { E[MPa] }\end{array}$ \\
\hline 0.53 & $\mathrm{DH} 2-55$ & $2.81-2.98$ & $68.3-69.9$ & $4790-4880$ \\
\hline 0.51 & $\mathrm{DH} 2-65$ & $2.67-2.87$ & $65.1-67.0$ & $4650-4720$ \\
\hline 0.52 & $\mathrm{DH} 2-75$ & $2.57-2.75$ & $61.2-63.1$ & $4580-4650$ \\
\hline
\end{tabular}

Based on the previously determined mechanical properties of these composite materials (with the Dammar-based hybrid resin matrix and the flax fabric reinforcement), we made a fixed orthosis (see Figure 12). The tensile strength and Young's modulus of the composite material used are high enough to ensure the protection of the tibia bone for a long period of time. In addition, the working time allows the orthosis to be shaped according to the shape of the anatomical segment. After use, by heating, the orthosis can then be remodelled according to subsequent changes in the immobilized segment (muscle atrophy). 
Such an orthosis provides protection against the loading of a bone segment from the tibia, by taking over a significant part of its physiological load.

The advantages of using the orthosis made of composite materials with the hybrid resin matrix based on Dammar and flax fabric reinforcement are:

- $\quad$ better tolerated by the human body (because it is made almost entirely of natural components that are allergic inert);

- increased mechanical efficiency, as there is as intimate contact as possible between the material of the orthosis and the skin covering the bone;

- can be easily shaped to take the shape of the human foot, namely it can be processed so as to be customized; by heating, the composite material with hybrid resin based on Dammar can be remodelled so that the orthosis is adapted for another user;

- low costs.

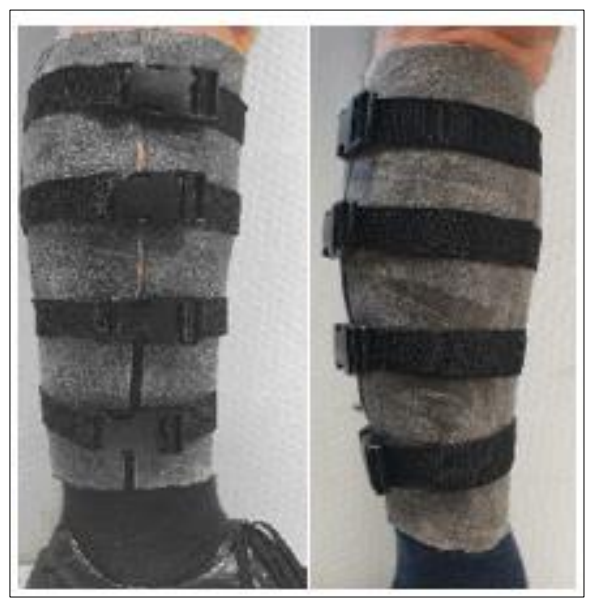

Figure 12. Orthosis made of hybrid resin based on

Dammar and flax fabric reinforcement

\section{Results and discussions}

The mechanical properties to be obtained are determined by the field in which the composite materials based on hybrid matrix and natural reinforcement are to be used. The adhesion between the resin and the reinforcing fibers is taken into account in the manufacture of composite materials. The type of hybrid resin, more precisely the mass proportion of the natural resin in the matrix, as well as the type of fibers influence this adhesion.

The variation of the mechanical properties of the three types of hybrid resin studied and of the composite materials labelled with DH1-55, DH1-65, DH1-75 and respectively DH2-55, DH2-65, DH275 , is presented below.

A fast decrease in the Young's modulus when the Dammar proportion is increased in the hybrid resin composition, from 2980-3070 MPa the hybrid resin with 55\% Dammar to 1700-1790 MPa of the hybrid resin with $75 \%$ Dammar was found out.

It is found that the tensile strength decreases to 26.8-28.8 MPa in the case of 55\% Dammar hybrid resin and to 12.1-13.6 $\mathrm{MPa}$ in the case of 75\% Dammar hybrid resin. The effect is the opposite of elongation at break, ie there is an increase when the proportion of Dammar is increased. The stress-strain diagram shows important changes. In the case of the 55\% Dammar hybrid resin, the stress-strain diagram is almost linear, while for the $75 \%$ Dammar hybrid resin the nonlinearity is significant.

The proportional variation of the volume of Dammar in the composition of the hybrid resin implies important changes of the mechanical properties of the studied composites. As the proportion of the volume of natural resin in the mixture increases, there is a decrease in the values of tensile strength and Young's modulus.

It is found that the variations in breaking strength values for hybrid resins used as matrices are larger than the variations in breaking strength of composer DH1 and DH2. The maximum tensile strength 
difference between the 55\% Dammar resin and the 75\% Dammar resin was $15.2 \mathrm{MPa}$, while in the case of DH1 and DH2 composites, the difference was between 6.8-9.9 MPa, for each type of reinforcement. In the case of composites DH1 and DH2, the Young module has even smaller variations. The maximum difference of the Young's modulus between Dammar 55\% resin and Dammar 75\% resin was $1300 \mathrm{MPa}$, while for DH1 composites the variation was $610 \mathrm{MPa}$ and for DH2 composites it was $230 \mathrm{MPa}$. A possible explanation may be that the fibers take over the stress from the beginning and the matrix has the role of supporting the fibers.

The main utility of this orthosis is related to the possibility to customize it, adapting it to the local anatomy of each patient. Its mechanical properties are close to those of prefabricated, standard orthoses, offering in addition the important advantage mentioned above. This fact is especially useful in cases with pseud arthrosis in which, in most cases, there is a deformation of the affected region which limits the use of standard orthoses. Moreover, the possibility of remodeling, according to the local evolution, is useful both from a mechanical point of view, permanently adapting it to this evolution, and from an economic perspective as well, not being necessary to change it frequently. Postoperative protection of congenital pseudarthrosis of the tibia in an ankle-foot orthosis made from this new material to avoid a new fracture of the region is another good indication, due to the reduced weight. This kind of orthosis can be used in the preoperative period as well in order to avoid the fracture or to delay the surgery. In some cases, orthosis can be used until skeletal maturity [31].

In 1963, Sarmiento introduced the functional cast for the management of fracture of the tibial shaft [26]. Some cases, due to the medical contraindications, are treated in an orthopaedic manner despite the surgical indication. Fot those cases the utility of a personalised orthosis, well adapted to the local anatomy of the involved segment is obvious, compared with traditional method (cast, resins, etc), due to the weight of orthosis and the posibility to reshape the orthosis according to local changes of the anatomical segment. The brace promotes fracture healing by compressing the soft tissue in the leg to limit its motion. The soft tissues surrounding the fracture, firmly compressed, prevented shortening and angulation by the principle of the incompressibility of fluids [32]. The philosophy of functional bracing is based upon principles which that micro movement at the site of a fracture during functional activities encourages osteogenesis $[33,34]$. Many studies confirmed that the strength of the callus which forms at the site of a fracture where micro movement occurs, like after bracing, is greater than that after rigid fixation provided by osteosynthesis [35].

Another strong recomandation is medical recovery after fractures. This orthosis will be installed for a certain period of time, to protect the fracture and ensures a certain rigidity in the specific situation where after removal of the cast there is a delay in consolidation.

Another future direction of development may be joint orthoses which due to the very good mechanical properties of the material in conditions of low thickness and reduced weight of it, can be particularly useful in case of chronic joint instabilities, when orthosis must be worn most of the time for a long period [36].

It is also recommended to use it in sports, like a protection for exposed anatomical regions. In the case of footbal players, this orthosis can offers better protection of the anterior aspect of the calf than comercial plastic protections, due to the better contact with the skin.

\section{References}

1.MOHANTY, A.K., MISRA, M., HINRICHSEN, G., Biofibers, biodegradable polymers and biocomposites: an overview, Macromol. Mater. Eng., 276-277, 2000, 1-24.

2.SHOGREN, R.L., PETROVIC, Z., LIU, Z.S., ERHAN, S.Z., Biodegradation behavior of some vegetable oil-based polymers, J. Polym. Environ., 12, 2004, 173-178.

3.UYAMA, H., KUWABARA, M., TSUJIMOTO, T., KOBAYASHI, S., Enzymatic synthesis and curing of biodegradable epoxide-containing polyesters from renewable resources, Biomacromolecules, 4, 2003, 211-215. 
4.MOHANTY, A.K., MISRA, M., DRZAL, T.L., Natural fibers, biopolymers and biocomposites, CRC Press Taylor\&Francis, 2005.

5.KANEHASHI, S., OYAGI, H., LU, R., MIYAKOSHI, T., Developement of bio-based hybrid resin, from natural lacquer, Prog. Org. Coat., 77, 2010, 24-29.

6.ISHIMURA, T., LU, R., YAMASAKI, K., MIYAKOSHI, T., Development of an eco-friendly hybrid lacquer based on kurome lacquer sap, Prog. Org. Coat., 69, 2010, 12-15.

7.DRISKO, G.L., SANCHEZ, C., Hybridization in materials science-Evolution, current state, and future aspirations, Eur. J. Inorg. Chem., 32, 2012, 5097-5105.

8.SCALARONE, D., DUURSMA, M.C., BOON, J.J., CHIANTORE, O., MALDI-TOF mass spectrometry on cellulosic surfaces of fresh and photo-aged di- and triterpenoid varnish resins, J. Mass Spectrom., 40, 2005, 1527-1535.

9.ECHARD, J.P., BENOIT, C., PERIS-VICENTE, J., MALECKI, V., GIMENO-ADELANTADO, J.V., VAIEDELICH, S., Gas chromatography/mass spectrometry characterization of historical varnishes of ancient Italian lutes and violin, Anal. Chim. Acta, 584, 2007, 172-180.

10.PETHE, A.M., JOSHI, S.B., Physicomedical, Mechanical and film forming studies of novel biomaterial, IJPSR, 4(7), 2013, 2761-2769.

11.ZAKARIA, R., AHMAD, A.H., Adhesion and hardness evaluation of modified silicone-Dammar as natural coating materials, Am. J. Appl. Sci., 9(6), 2012, 890-893.

12.ZAKARIA, R., AHMAD, A.H., The performance of modified silicone-Dammar resin in nanoindentation test, Int. J. Adv. Sci. Technol., 42, 2012, 33-44.

13.HIDAYAT, A.T., FARABI, K., HARNETI, D., MAHARANI, R., MAYANTI, T., SETIAWAN, A.S., SUPRATMAN, U., SHIONO, Y., Cytotoxicity and structure activity relationship of Dammaranetype triterpenoids from the bark of aglaia elliptica against P-388 murine leukemia cells, Nat. Prod. Sci., 23, 2017, 291-298.

14.FRANZ, M.H., NEDA, I., MAFTEI, C.V., CIUCA, I., BOLCU, D., STANESCU, M.M., Studies of chemical and mechanical properties of hybrid composites based on natural resin Dammar formulated by epoxy resin, Polym. Bull., 2020 (online) https://doi.org/10.1007/s00289-020-03221-4

15.SHARMA, P., MITTAL, H., JINDAL, R., JINDAL, D., ALHASSAN, S.M., Sustained delivery of atenolol drug using gum Dammar crosslinked polyacrylamide and zirconium based biodegradable hydrogel composites, Colloids Surf. A Physicochem. Eng. Asp., 562, 2019, 136-145.

16.SHARMA, P., JINDAL, R., MAITI, M., JANA, A.K., Novel organic-inorganic composite material as a cation exchanger from a triterpenoidal system of Dammar gum: synthesis, characterization and application, Iran Polym. J., 25, 2016, 671-685.

17.SHARMA, P., JINDAL, R., MAITI, M., Studies on gum Dammar based composite ion exchanger and their characterization, Polym. Bull., 75, 2018, 1365-1385.

18.SHARMA, P., JINDAL, R., Gum Dammar and poly(acrylamide)-based hydrogels and zirconiumbased organic-inorganic hybrid materials for controlled drug delivery and their biodegradation studies, Polym. Bull., 75, 2018, 4175-4190.

19.LI, X., TABIL, L.G., PANIGRAHI, S., CRERAR, W.J., The influence of fiber content on properties of injection molded flax fiber-HDPE biocomposites, Can. Biosyst. Eng., 08-148, 2009, 1-10.

20.OKSMAN, K., Mechanical properties of natural fibre mat reinforced thermoplastic, Appl. Compos. Mater., 7, 2000, 403-414.

21.MOHANTY, A.K., MISRA, M., DRZAL, L.T., Sustainable bio-composites from renewable resources: opportunities and challenges in the green materials world, J. Polym. Environ., 10, 2002, 1926.

22.SREEKALA, M.S., THOMAS, S., Effect of fibre surface modification on watersorption characteristics of oil palm fibres, Compos. Sci. Technol., 63(6), 2003, 861-869.

23.SREEKALA, M.S., KUMARAN, M.G., THOMAS, S., Water sorption in oil palm fiber reinforced phenol formaldehyde composites, Composites A, 33(6), 2002, 763-777. 
24.STĂNESCU, M.M., BOLCU, D., A study of some mechanical properties of a category of composites with a hybrid matrix and natural reinforcements, Polymers, 11(3), 2019, 1-16.

25.BOLCU, D., STĂNESCU, M.M., The influence of non-uniformities on the mechanical behaviour of hemp-reinforced composite materials with a Dammar matrix, Materials, 12(8), 2019, 1-15.

26.SARMIENTO, A., GERSTEN, L.M., SOBOL, P.A., SHANKWILER, J.A., VANGSNESS, C.T., Tibial shaft fractures treated with functional braces: experience with 780 fractures, J Bone Joint Surg., 1989, 71(B), 602-609.

27.RESOLTECH 1050, hardeners 1053 to 1059. Structural Lamination Epoxy System. Available online: www.scabro.com/images/.../1/.../Resoltech\%201050/DS-1050.pdf (accessed on January 09, 2019).

28.***ASTM D3039, Standard Test Method for Tensile Properties of Polymer Matrix Composite Materials. Available online: https://www.astm.org/Standards/D3039 (accessed on January 09, 2019).

29.KABIR, M.M., WANG, H., LAU, K.T., CARDONA, F., Chemical treatments on plant-based natural fibre reinforced polimer composite: An overview, Compos. B. Eng., 43, 2012, 2883-2892.

30.MEI-PO, H., WANG, H., JOONG-HEE, L., KIN-TAK, L., JINSONG, L., HUI, D., Critical factors on manufacturing processes of natural fibre composites, Compos. B. Eng., 43, 2012, 3549-3562.

31.YOUNG, J., Ankle-foot orthoses in the pre and post operative management of Congenital Pseudarthrosis of the Tibia. Two case reports, Conference: British Association of Prosthetists and Orthotists conference 2019 (BAPO), Harrogate, U.K., 15-17 March 2019, https://doi.org/10.13140/RG.2.2.14192.10242

32.RAIKIN, S.M., PARKS, B.G., NOLL, K.H., SCHON, L.C., Biomechanical evaluation of the ability of casts and braces to immobilize the ankle and hind foot, Foot Ankle Int., 22(3), 2001, 214-219.

33.SARMIENTO, A., LATTA, L.L., TARR, R., The effects of function in fracture healing and stability. In: Murray J.A., ed. Instructional course lectures. St. Louis: C.V. Mosby Co., 1984, 83-106.

34.SARMIENTO, A., MULLIS, D., LATTA, L.L., ALVAREZ, R., A quantitative comparative analysis of fracture healing under the influence of compression plating versus closed weight bearing treatment, Clin. Orthop., 232, 1980, 232-239.

35.SARMIENTO, A., MCKELLOP, H., LLINAS, A., Effect of loading and fracture motions on diaphyseal tibial fractures, J. Orthop. Res., 14, 1996, 80-84.

36.KENWRIGHT, J., GOODSHIP, A., KELLY, D., et al., Effect of controlled axial micro motion on healing of tibial fractures, Lancet, 2, 1986, 1185-1187

Manuscript received: 2.11 .2020 